\title{
Comparison of peak oxygen uptake and exercise efficiency between upper-body poling and arm crank ergometry in trained paraplegic and able-bodied participants
}

\author{
Julia Kathrin Baumgart ${ }^{1}$ (D) Laura Gürtler $^{1} \cdot$ Gertjan Ettema $^{1}$ (D) $\varnothing_{\text {yvind Sandbakk }}^{1}$ (D)
}

Received: 8 December 2017 / Accepted: 30 May 2018 / Published online: 23 June 2018

(c) The Author(s) 2018

\begin{abstract}
Purpose To compare peak oxygen uptake $\left(\mathrm{VO}_{2 \text { peak }}\right)$ and exercise efficiency between upper-body poling (UBP) and arm crank ergometry (ACE) in able-bodied (AB) and paraplegic participants (PARA).

Methods Seven PARA and eleven AB upper-body trained participants performed four 5-min submaximal stages, and an incremental test to exhaustion in UBP and ACE. $\mathrm{VO}_{2 \text { peak }}$ was the highest 30-s average during the incremental test. Metabolic rate (joule/second = watt) at fixed power outputs of 40,60, and $80 \mathrm{~W}$ was estimated using linear regression analysis on the original power-output-metabolic-rate data and used to compare exercise efficiency between exercise modes and groups.

Results $\mathrm{VO}_{2 \text { peak }}$ did not significantly differ between UBP and ACE $(p=0.101)$, although peak power output was $19 \%$ lower in UBP $(p<0.001)$. Metabolic rate at fixed power outputs was $24 \%$ higher in UBP compared to ACE $(p<0.001)$, i.e., exercise efficiency was lower in UBP. PARA had $24 \%$ lower $\mathrm{VO}_{2 \text { peak }}$ compared to $\mathrm{AB}(p=0.010)$, although there were no significant differences in peak power output between PARA and $\mathrm{AB}(p=0.209)$.

Conclusions In upper-body-trained PARA and $\mathrm{AB}$ participants, $\mathrm{VO}_{2 \text { peak }}$ did not differ between UBP and ACE, indicating that these two test modes tax the cardiovascular system similarly when the upper body is restricted. As such, the $19 \%$ lower peak power output in UBP compared to ACE may be explained by the coinciding lower efficiency.
\end{abstract}

Keywords Aerobic power $\cdot$ Endurance $\cdot$ Paralympic $\cdot$ Spinal cord injury $\cdot \mathrm{VO}_{2 \max } \cdot \mathrm{VO}_{2 \text { peak }}$

$\begin{array}{ll}\text { Abbreviations } \\ \text { AB } & \text { Able-bodied participants } \\ \text { ACE } & \text { Arm crank ergometry } \\ \text { BLa } & \text { Blood lactate } \\ \text { HR } & \text { Heart rate } \\ \text { MR } & \text { Metabolic rate } \\ \text { PARA } & \text { Participants with a paraplegia } \\ \text { PO } & \text { Power output } \\ \text { RER } & \text { Respiratory exchange ratio }\end{array}$

Communicated by Jean-René Lacour.

Electronic supplementary material The online version of this article (https://doi.org/10.1007/s00421-018-3912-1) contains supplementary material, which is available to authorized users.

Julia Kathrin Baumgart

jk.baumgart@gmail.com

1 Centre for Elite Sports Research, Department of Neuromedicine and Movement Science, Norwegian University of Science and Technology, Smistadgrenda 11, 7026 Trondheim, Norway

$\begin{array}{ll}\mathrm{RPE} & \text { Overall rating of perceived exertion } \\ \mathrm{UBP} & \text { Upper-body poling } \\ \mathrm{VE} & \text { Minute ventilation } \\ \mathrm{VO}_{2} & \text { Oxygen uptake } \\ \mathrm{VO}_{2 \text { peak }} & \text { Peak oxygen uptake }\end{array}$

\section{Introduction}

Peak oxygen uptake $\left(\mathrm{VO}_{2 \text { peak }}\right)$ and exercise efficiency are key factors for endurance performance. In persons who are primarily able to use their upper-body during exercise, such as many paralympic athletes, the mode most commonly used in assessing $\mathrm{VO}_{2 \text { peak }}$ and efficiency is arm crank ergometry (ACE) (Drory et al. 1990; Glaser et al. 1980; Mossberg et al. 1999; Price et al. 2011; Smith et al. 2001, 2004, 2006, 2007; Tropp et al. 1997). However, sport-specificity of the test mode has been suggested to be of importance for achieving $\mathrm{VO}_{2 \text { peak }}$ and efficiency that are reflective of the endurance capacity in the respective sport (McCafferty and Horvath 1977). For para ice hockey players, sitting para cross-country skiers and 
para biathletes, the upper-body poling (UBP) movement is the most sport specific. However, it has not yet been investigated whether $\mathrm{VO}_{2 \text { peak }}$ and efficiency differ between ACE and UBP and if possible differences are caused by the respective movement of the arms and/or due to different use of the trunk.

In ACE, power is produced by continuous, asynchronous force application, whereas in UBP-similarly to wheelchair ergometry-power is generated discontinuously, yet in synchronous movements of both hands (Sawka 1986). During ACE, the involvement of the trunk is limited by the asynchronous movement of the hands, whereas during UBP and wheelchair ergometry the synchronous movement of the hands allows more involvement of the trunk. A higher $\mathrm{VO}_{2 \text { peak }}$ may, therefore, be expected in UBP and wheelchair ergometry compared to ACE due to using more muscle mass. However, despite the differences in arm movement and the engagement of the trunk between ACE and wheelchair ergometry, some studies show no differences in $\mathrm{VO}_{\text {2peak }}$ values between these two modes (Arabi et al. 1997; Gass et al. 1995; Gayle et al. 1990; Glaser et al. 1980; Martel et al. 1991; Price and Campbell 1999b), whereas others report higher values in the wheelchair ergometry mode (Bloemen et al. 2015; Gass and Camp 1984; Sawka et al. 1980). Furthermore, previous studies have shown that wheelchair ergometry is less efficient than ACE (Glaser et al. 1980; Hintzy et al. 2002; Mukherjee and Samanta 2001). This is likely caused by higher coordinative demands of using the discontinuous movement and by production of power during a shorter portion of each cycle in the wheelchair ergometry mode (Mukherjee and Samanta 2001).

Irrespective of the upper-body mode used during exercise testing, $\mathrm{VO}_{2 \text { peak }}$ values were found to be consistently lower in paraplegic (PARA) compared to able-bodied participants (AB) (Price and Campbell 1999a; Hopman et al. 2004; Leicht and Perret 2008). Although the evidence is currently limited, efficiency in both ACE and wheelchair ergometry does not seem to differ between PARA and AB (Glaser et al. 1980).

In the current study, we aimed to compare $\mathrm{VO}_{2 \text { peak }}$ and exercise efficiency between ACE and UBP with the upperbody restricted in both modes in PARA and AB. We hypothesized that $\mathrm{VO}_{2 \text { peak }}$ values would be similar in $\mathrm{ACE}$ and UBP, yet lower in PARA as compared to AB. In accordance with the lower efficiency previously found in wheelchair ergometry, exercise efficiency was expected to be lower in UBP compared to ACE in the current study.

\section{Methods}

\section{Participants}

The PARA group consisted of seven (6 men, 1 women) upper-body-trained individuals with a paraplegia and the
AB group of eleven ( 9 men, 2 women) healthy able-bodied upper-body-trained controls (anthropometrics and training hours are presented in Table 1). PARA were significantly older and had significantly lower leg lean muscle mass (LLM) compared to AB (both comparisons, $p<0.004$ ). PARA consisted of an ice sledge hockey player, two handcyclists, a wheelchair curler, a wheelchair judoist and two recreationally trained participants. $\mathrm{AB}$ were sub-elite cross-country skiers who trained $11.5 \pm 3.2 \mathrm{~h} /$ week, with approximately half of this training spent in modes including the upper-body. Whereas the total number of training sessions was significantly higher in $\mathrm{AB}(7.2 \pm 2.9$ sessions/ week, $p=0.009$ ), training sessions including upper-body exercise did not differ between AB and PARA (4.5 \pm 2.4 versus $4.0 \pm 1.9$ sessions/week, $p=0.687)$. The participants were instructed to refrain from heavy training and alcohol consumption $24 \mathrm{~h}$ before the start of the testing, caffeine intake the day of the testing and food intake $2 \mathrm{~h}$ before testing. A questionnaire was filled in on each test day to monitor if the participants followed these instructions, as well as to exclude any prior illness or injury that might interfere with the testing. Participants provided written informed consent to voluntarily take part in the study and were informed about the possibility to withdraw from the study at any point in time without providing the reason for doing so. All procedures performed in studies involving human participants were in accordance with the ethical standards of the Regional Ethics Committee for Medical and Health Research in Mid-Norway and with the 1964 Helsinki Declaration and its later amendments. The study was retrospectively registered in the Protocol Registration and Results System (NCT03284086).

\section{Overall design}

The testing consisted of two test days, where participants performed four 5-min submaximal steady-state stages, an incremental test to exhaustion and a verification stage in UBP or ACE in a counterbalanced order. Tests were performed at the same time of day to minimize the bias of diurnal variation in performance (Atkinson and Reilly 1996). The time between tests was a minimum of $48 \mathrm{~h}$ and a maximum of 4 days. On a separate day before or after the testing, body composition was assessed using dual-energy X-ray absorptiometry (DXA).

\section{Test set-up}

After being equipped with an oro-nasal mask (Hans Rudolph Inc, Kansas City, MO, USA) and a heart rate monitor (Polar Electro Inc., Port Washington, NY, USA), participants were tightly strapped into a seat construction, which consisted of a modified weight lifting bench placed 


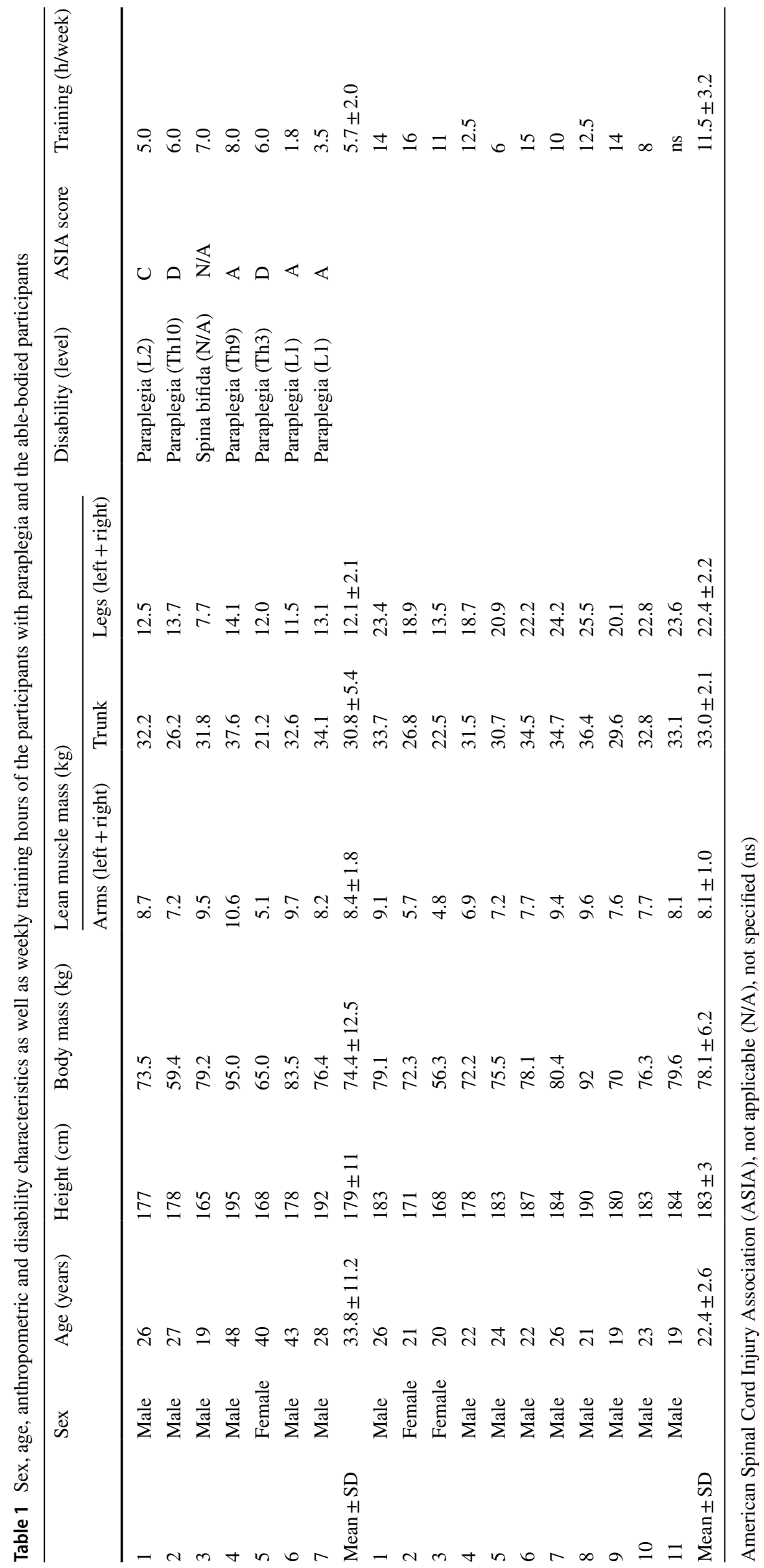


in front of the UBP or ACE ergometer (see Fig. 1a, b). The upper-body was fixed during all tests to limit differences in involvement of the trunk between UBP and ACE as well as $\mathrm{AB}$ and PARA. Furthermore, the legs were supported and fixed to minimize leg muscle activation. The spiroergometer (Oxycon Pro, Jaeger, Viasys BV, Bilthoven, the Netherlands) was calibrated against a known mixture of gases $\left(15 \% \mathrm{O}_{2}, 5 \% \mathrm{CO}_{2}\right)$. The flow transducer was calibrated with a 3-L syringe (Calibration syringe D, SensorMedics, Yorba Linda, CA, USA). Respiratory parameters were assessed by open-circuit calorimetry, with expired gases passing through a mixing chamber and being measured continuously. The Concept 2 ski-ergometer (Concept2, Morrisville, USA) was used during testing in the UBP mode. An ErgStick (Endurance Sports Research Limited, United Kingdom) was connected to the PM4 monitor of the Concept2 ski ergometer and the application Float (ErgStick Ltd, United Kingdom) continuously recorded power output (PO) and stroke rate. The ergometer's software has previously been validated with force and velocity measurements (Hegge et al. 2015). The ACE was custom-made from a road-bike (White, XXL Sport \& Villmark AS, Norway) and equipped with an electronical brake system for indoor cycling (CompuTrainer ${ }^{\mathrm{TM}}$, RacerMate ${ }^{\circledR}$, Inc., Seattle, USA). The crank axis was aligned with the participant's shoulder height and the seat positioned so that the participant's elbows were slightly bent at maximal reach. The tire pressure was kept stable at six bars and the CompuTrainer ${ }^{\mathrm{TM}}$ was calibrated prior to each test session. The in-built software (PerfPRO Studio $\odot$, Dynastream Innovations Inc., Canada) continuously recorded PO and crank rate.

\section{Test protocol}

\section{Submaximal stages}

Prior to testing, participants familiarized themselves with the test set-up by 5 min of arm cranking or upper-body poling at low intensity [overall rating of perceived exertion (RPE) $8-9]$. The testing then commenced by performing four times 5-min submaximal stages at overall RPEs of 9 (very light), 11 (light), 13 (somewhat hard) and 15 (hard) on a 6-20 Borg scale (Borg 1982). Target RPE at increasing intensities from 9 to 15 (Hegge et al. 2015) was used instead of fixed workloads to ensure that the participants covered a similar range of exercise intensities relative to their maximal capacity. In the ACE mode, crank rate was self-chosen within 60-90 revolutions per minute, whereas stroke rate in the UBP mode was fully self-chosen.

Oxygen uptake $\left(\mathrm{VO}_{2}\right)$, respiratory exchange ratio (RER) and minute ventilation (VE) were recorded as 10-s averages. Heart rate (HR) was recorded every second. PO was recorded every second in ACE, and for every stroke in UBP and then interpolated at 1-s intervals. After each submaximal stage, there was a 2- to 3-min break during which a $20 \mu \mathrm{L}$ blood sample was taken from the fingertip and blood lactate (BLa) measured with the Biosen C-Line Sport lactate measurement system (EKF-diagnostic GmbH, Magdeburg, Germany). Furthermore, overall RPE was recorded. Steadystate $\mathrm{PO}, \mathrm{VO}_{2}, \mathrm{RER}, \mathrm{VE}$, and $\mathrm{HR}$, were calculated by averaging the values during the last 2 min of each submaximal stage. There are three primary ways to describe mechanical efficiency during exercise: delta efficiency, net efficiency and gross efficiency. In brief, the challenges with net efficiency and delta efficiency, which are outlined more in detail by Ettema and Lorås (2009), concern the assumption that the
Fig. 1 Test set-up with the participant in a sitting position with the upper-body and the legs fixed in front of the Concept2 ski-ergometer (a) and the arm crank ergometer (b)

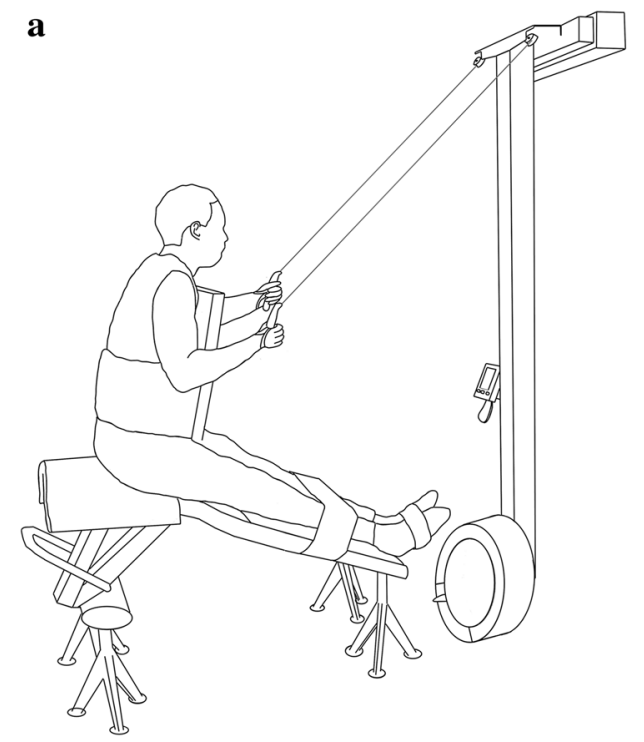

b

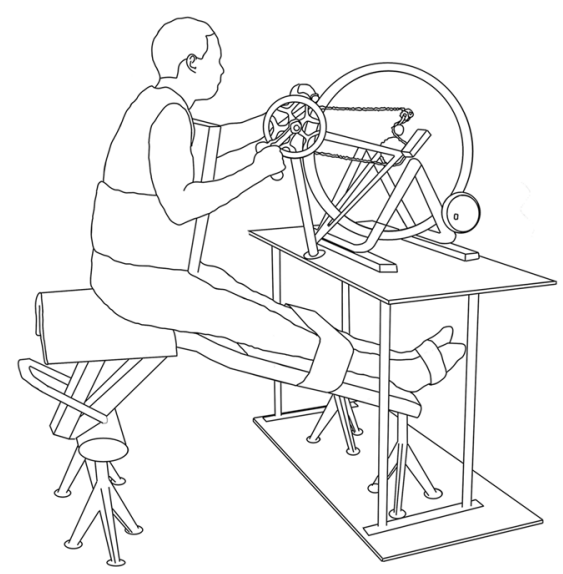


processes related to the resting metabolism are independent of the processes associated with producing work. In comparison, gross efficiency, which is the ratio of $\mathrm{PO}$ and metabolic rate (MR), is a theoretically sound concept. However, it is affected by the diminishing effect of the resting metabolism with increasing PO. Therefore, we also consider the entire PO-MR relationship to interpret exercise efficiency in the current study.

MR in joule/second (watt) was calculated from $\mathrm{VO}_{2}$ and RER with the use of a standard conversion table (Peronnet and Massicotte 1991). MR was then estimated from the original PO-MR relationship at a PO of 40,60 and $80 \mathrm{~W}$ using linear regression analyses in Matlab R2016a (MathWorks Inc., Natic, USA). The resulting MR outcomes were used to investigate exercise efficiency between exercise modes and groups. In addition, gross efficiency was calculated as MR divided by $\mathrm{PO}$ at 40,60 and $80 \mathrm{~W}$.

\section{Incremental test to exhaustion}

After a 5-min passive break and a 3-min active recovery at the workload equivalent to the first stage (RPE 9), the participants performed an incremental test to exhaustion. The incremental test started at the individual PO of the second submaximal stage (RPE 11) (rounded to the nearest 10-W value) of the respective mode. PO was then increased by $10 \mathrm{~W}$ every $1 \mathrm{~min}$. Termination criteria were a drop in PO and a plateau ( 3 values with $<2 \mathrm{~mL} \cdot \mathrm{kg}^{-1} \cdot \mathrm{min}^{-1}$ difference) (Taylor et al. 1955) or drop in $\mathrm{VO}_{2}\left(>2 \mathrm{~mL} \cdot \mathrm{kg}^{-1} \cdot \mathrm{min}^{-1}\right)$. BLa was measured 1 and 3 min after the incremental test. Furthermore, overall RPE was recorded directly after the incremental test. After a 5-min passive break and a 3-min active recovery, participants performed a verification stage where they directly increased the workload to the peak PO of the incremental test to verify that no higher $\mathrm{VO}_{2 \text { peak }}$ can be obtained despite a longer duration spent at high workload (Leicht et al. 2013).

30 -s moving averages were calculated for the $\mathrm{PO}$ and the respiratory parameters and the highest values were defined as peak values. 3-s moving averages were calculated for the HR data and the highest value defined as peak HR. The higher of the two blood lactate values was defined as peak BLa.

\section{Statistics}

A linear mixed model with fixed coefficients and random intercept was employed to investigate the effect of exercise mode, group and exercise intensity on PO, physiological and perceptual parameters during the submaximal stages and the incremental test. This model investigates the effect of one factor (exercise mode or group or exercise intensity) while adjusting for the two other factors. The same model was used to investigate the effect of exercise mode and group on exercise efficiency. Paired-samples $T$ tests were used to compare gross efficiency between exercise modes and groups at each of the three POs. An alpha level of 0.05 was used to indicate statistical significance. IBM SPSS Statistics 24.0 (SPSS Inc., Chicago, USA) was used for all statistical analyses.

\section{Results}

\section{Peak values from incremental test}

An overview of the peak values reached during the incremental test is provided in Table 2. During UBP, when group was adjusted for, participants produced $19 \%$ lower peak PO compared to ACE $(p<0.001)$ but displayed 0.08 higher RER $(p<0.001)$. PARA had a $24 \%$ lower $\mathrm{VO}_{2 \text { peak }}$ $(p=0.010)$ and 1.2 higher $\operatorname{RPE}(p=0.018)$ compared to AB. However, peak PO did not significantly differ between PARA and AB despite being 14\% lower in PARA compared to $\mathrm{AB}(p=0.209)$. A significant interaction in peak VE existed between exercise mode and group $(p=0.049)$. When investigating each group separately, AB displayed a trend towards a $22 \%$ higher peak VE in UBP compared to $\operatorname{ACE}(p=0.069)$, whereas in PARA there was no significant difference between modes $(p=0.804)$.

\section{Submaximal values}

All outcome parameters significantly increased from the first stage (RPE 9) to the fourth stage (RPE 15) (all comparisons, $p<0.001$ ) (Fig. 2a, b). During UBP, at a given RPE, participants produced $16 \%$ lower PO $(p<0.001)$ and displayed $7 \%$ higher $\mathrm{VO}_{2}(p=0.005), 9 \%$ point higher $\%$ of $\mathrm{VO}_{2 \text { peak }}(p<0.001), 8 \%$ higher MR $(p=0.001), 0.04$ higher RER $(p<0.001), 19 \%$ higher VE $(p<0.001), 6 \%$ higher HR $(p=0.001), 7 \%$ point higher $\%$ of peak HR $(p<0.001)$ and $0.50 \mathrm{mmol} \cdot \mathrm{L}^{-1}$ higher BLa $(p=0.002)$ compared to ACE. PARA had a trend towards $18 \%$ lower PO $(p=0.081)$ and displayed 20\% lower $\mathrm{VO}_{2}(p=0.016)$ and $22 \%$ lower MR $(p=0.046)$. No significant differences between neither modes nor groups were found in $\%$ of peak PO and $\%$ of peak VE (all comparisons, $p>0.689$ ). No significant differences between groups were found in $\%$ of $\mathrm{VO}_{2 \text { peak }}, \mathrm{VE}, \mathrm{RER}$, HR, \% of peak HR and BLa (all comparisons, $p<0.283$ ). Furthermore, no significant differences in RPE at 30, 40, 50 and $60 \%$ of $\mathrm{VO}_{2 \text { peak }}$ were found $(p=0.993)$.

\section{Exercise efficiency}

MR was $24 \%$ higher in UBP compared to ACE $(p<0.001)$, i.e., exercise efficiency was lower in UBP (Fig. 3a). In line with this, gross efficiency calculated at 40,60 and $80 \mathrm{~W}$ 
Table 2 Peak power output, peak physiological and perceptual responses $($ Mean $\pm \mathrm{SD}$ ) during the incremental test to exhaustion in the upper-body poling and arm crank ergometry mode in the seven paraplegic and eleven able-bodied participants

\begin{tabular}{|c|c|c|c|c|}
\hline & \multicolumn{2}{|c|}{ Upper-body poling } & \multicolumn{2}{|c|}{ Arm crank ergometry } \\
\hline & Paraplegic & Able bodied & Paraplegic & Able bodied \\
\hline \multirow[t]{2}{*}{ Peak PO (Watt) } & $118 \pm 34$ & $118 \pm 34$ & $146 \pm 33 *$ & $146 \pm 33 *$ \\
\hline & $104 \pm 35$ & $127 \pm 31$ & $136 \pm 38$ & $152 \pm 29$ \\
\hline \multirow[t]{2}{*}{$\mathrm{VO}_{2 \text { peak }}\left(\mathrm{mL} \cdot \mathrm{kg}^{-1} \cdot \mathrm{min}^{-1}\right)$} & $35.9 \pm 7.8$ & $35.9 \pm 7.8$ & $37.3 \pm 8.0$ & $37.3 \pm 8.0$ \\
\hline & $30.3 \pm 6.1$ & $39.5 \pm 6.6^{\dagger}$ & $32.7 \pm 7.0$ & $40.3 \pm 7.3^{\dagger}$ \\
\hline \multirow[t]{2}{*}{ Peak VE $\left(\mathrm{L} \cdot \mathrm{min}^{-1}\right)$} & $145 \pm 37 *$ & $145 \pm 37 *$ & $126 \pm 40$ & $126 \pm 40$ \\
\hline & $131 \pm 47$ & $154 \pm 28$ & $124 \pm 44$ & $126 \pm 39$ \\
\hline \multirow[t]{2}{*}{ Peak RER } & $1.19 \pm 0.05^{*}$ & $1.19 \pm 0.05^{*}$ & $1.11 \pm 0.06$ & $1.11 \pm 0.06$ \\
\hline & $1.20 \pm 0.05$ & $1.19 \pm 0.06$ & $1.15 \pm 0.06^{\dagger}$ & $1.09 \pm 0.04$ \\
\hline \multirow[t]{2}{*}{ Peak HR (beats. $\min ^{-1}$ ) } & $176 \pm 16$ & $176 \pm 16$ & $178 \pm 17$ & $178 \pm 17$ \\
\hline & $172 \pm 20$ & $178 \pm 14$ & $182 \pm 14$ & $176 \pm 18$ \\
\hline \multirow[t]{2}{*}{ Peak BLa $\left(\mathrm{mmol} \cdot \mathrm{L}^{-1}\right)$} & $10.8 \pm 1.9$ & $10.8 \pm 1.9$ & $9.9 \pm 3.0$ & $9.9 \pm 3.0$ \\
\hline & $10.2 \pm 2.3$ & $11.3 \pm 1.5$ & $10.3 \pm 3.7$ & $9.6 \pm 2.6$ \\
\hline \multirow[t]{2}{*}{ RPE (6-20) } & $18.8 \pm 1.2$ & $18.8 \pm 1.2$ & $18.4 \pm 1.2$ & $18.4 \pm 1.2$ \\
\hline & $19.3 \pm 0.5$ & $18.5 \pm 1.4$ & $19.2 \pm 0.6^{\dagger}$ & $17.8 \pm 1.2$ \\
\hline
\end{tabular}

Power output $(\mathrm{PO})$, peak oxygen uptake $\left(\mathrm{VO}_{2 \text { peak }}\right)$, minute ventilation $(\mathrm{VE})$, respiratory exchange ratio (RER), heart rate (HR), blood lactate (BLa), overall rating of perceived exertion (RPE)

*Significantly higher in either upper-body poling or arm crank ergometry at an alpha level of 0.05

${ }^{\dagger}$ Significantly higher in either able-bodied or paraplegic participants at an alpha level of 0.05 was significantly lower in UBP $(10.4 \pm 0.9,11.4 \pm 0.8$ and $12.0 \pm 0.9)$ compared to ACE $(12.9 \pm 1.8,14.0 \pm 1.8$ and $14.7 \pm 1.9$ ) (all comparisons $p<0.001)$. MR was not significantly different between PARA and AB $(p=0.323)$ (Fig. 3b, c).

\section{Discussion}

The aim of this study was to compare $\mathrm{VO}_{2 \text { peak }}$ and exercise efficiency between upper-body poling (UBP) and arm crank ergometry (ACE) in paraplegic (PARA) and able-bodied (AB) participants. As expected, $\mathrm{VO}_{2 \text { peak }}$ did not differ between UBP and ACE, indicating that both modes tax the cardiovascular system similarly. However, there was a $19 \%$ lower peak power output (PO) produced in UBP that coincided with the $24 \%$ higher metabolic rate (MR) at a given PO (i.e., lower gross efficiency). PARA did not differ from $\mathrm{AB}$ in exercise efficiency, but PARA had $24 \%$ lower $\mathrm{VO}_{2 \text { peak }}$ compared to $\mathrm{AB}$.

\section{Differences between UBP and ACE}

This is the first study to investigate differences in $\mathrm{VO}_{2 \text { peak }}$ and exercise efficiency between UBP and ACE. We found no difference in $\mathrm{VO}_{2 \text { peak }}$ between UBP and ACE, which indicates that-with the upper-body restricted-the cardiorespiratory system is taxed equally in both exercise modes when working until voluntary exhaustion. In addition, no differences in peak HR, peak BLa and RPE were found between UBP and ACE, indicating that a similar level of exhaustion was reached at the end of the tests. However, although the peak aerobic energy delivery capacity and the ability to reach exhaustion did not differ between exercise modes, peak PO was clearly lower in UBP compared to ACE. The difference in peak PO is likely explained by UBP being a less efficient test mode, which is also supported by lower efficiency in UBP compared to ACE at submaximal workloads.

The higher MR at a given power (i.e., lower gross efficiency) in UBP may be related to that power is produced in a discontinuous movement, which includes larger fluctuations in instantaneous power, compared to in ACE where the movement is more continuous. In line with this, studies comparing wheelchair propulsion to ACE have found that the discontinuous movement during wheelchair propulsion is less efficient (Hintzy et al. 2002; Glaser et al. 1980; Mukherjee and Samanta 2001). Discontinuous force application has been shown to increase power fluctuations within strokes, a strategy that costs more for the production of the same PO (Glaser et al. 1980). Furthermore, in UBP, the participants move their arms up against gravity before pulling down on the ropes. This movement fundamentally differs from ACE where the arms are supported by the cranks throughout the whole cycle, a movement pattern that has previously been associated with higher exercise efficiency compared to wheelchair propulsion (Mukherjee and Samanta 2001), arguably due to reutilization of kinetic energy. Altogether, the lower exercise efficiency in UBP compared to ACE may be explained by the different movement characteristics. 
Fig. 2 Power output and physiological parameters at a rating of perceived exertion (RPE) of $9,11,13$ and 15 presented both as absolute values and as percentage of peak. Furthermore, RPE is presented at $30,40,50$ and $60 \%$ of peak oxyen uptake $\left(\mathrm{VO}_{2 \text { peak }}\right)($ Circles represent the UBP mode, squares the ACE mode. Open symbols represent the PARA participants, closed symbols the $\mathrm{AB}$ participants). Oxygen uptake $\left(\mathrm{VO}_{2}\right)$
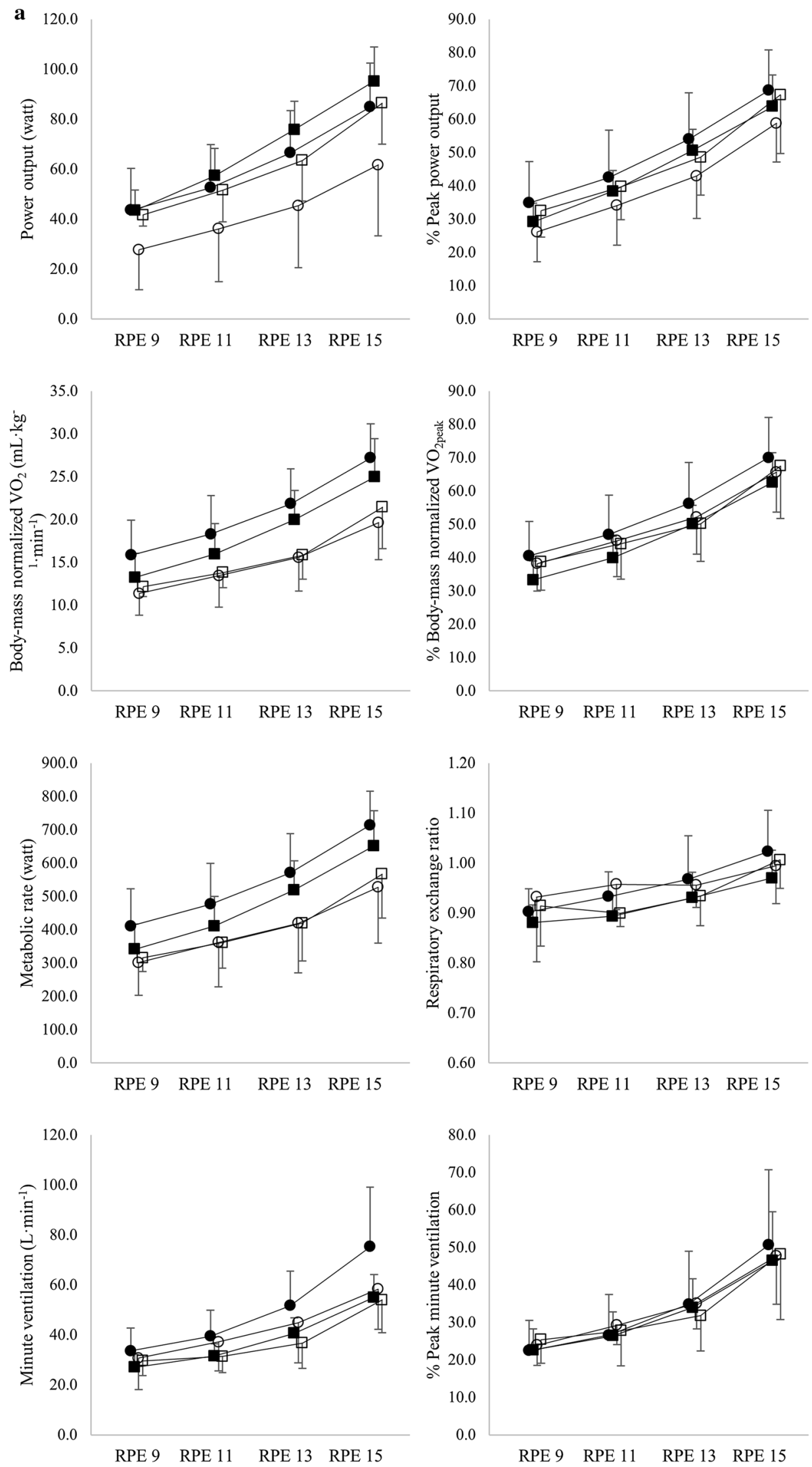
Fig. 2 (continued)
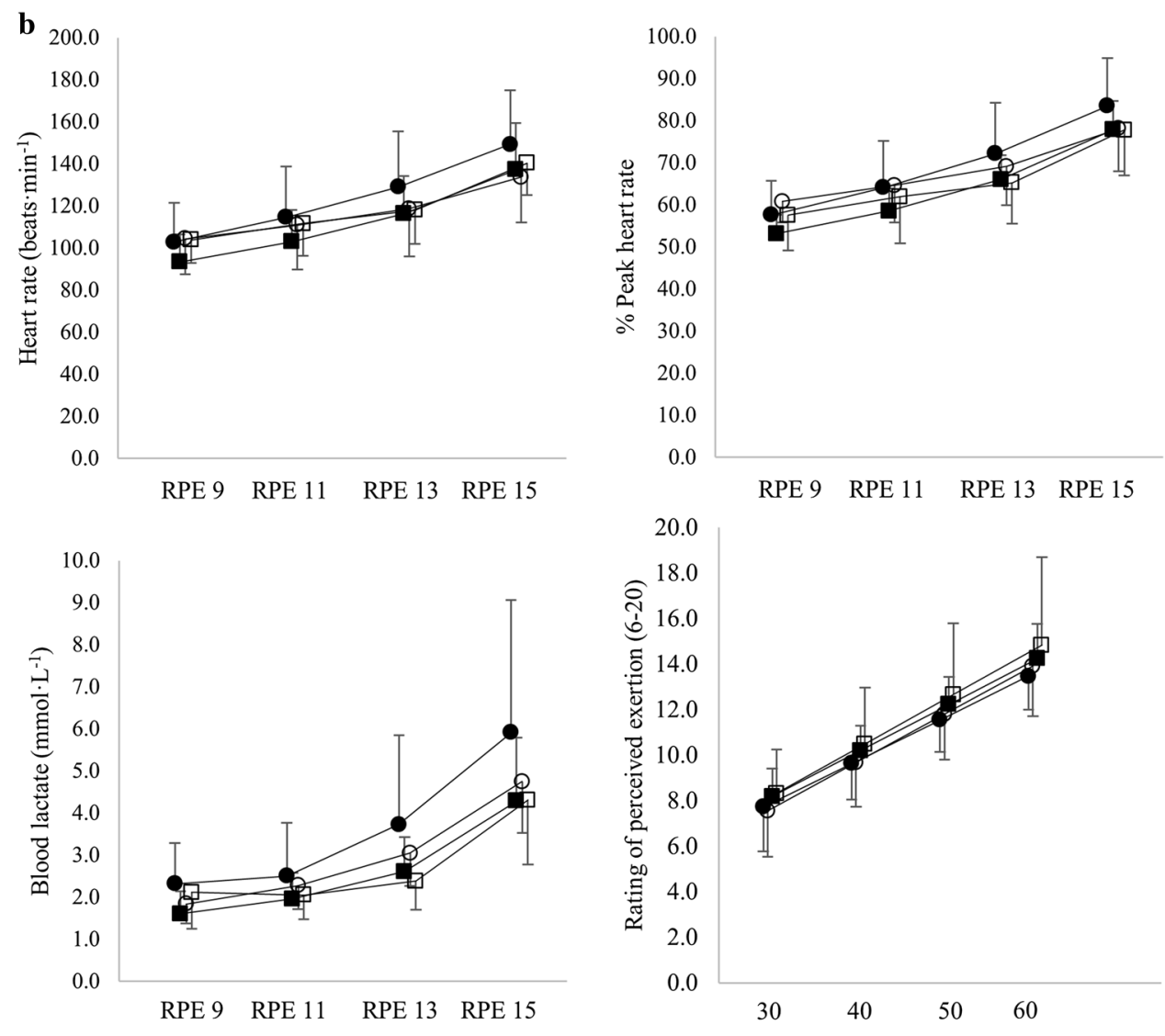

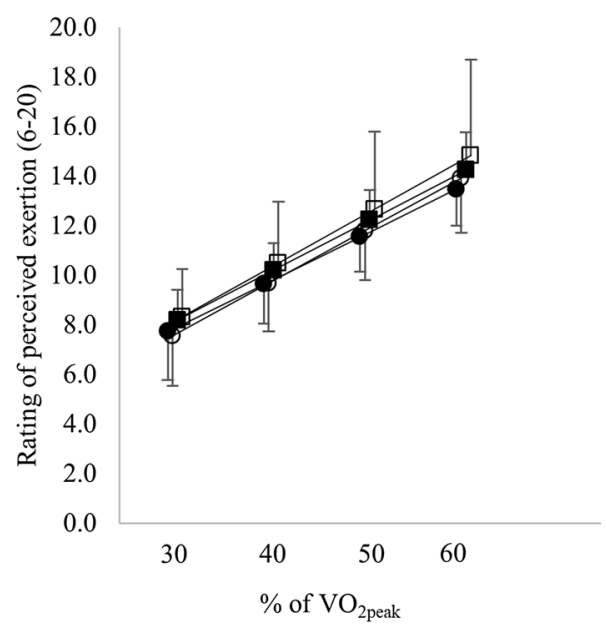

The $\%$ of peak PO employed at the various RPE-matched submaximal stages was almost identical between UBP and ACE. However, UBP showed a higher MR and a trend towards lower absolute PO during each of these stages, which is associated with the lower exercise efficiency in UBP. In addition, all related physiological outcome parameters (e.g., $\mathrm{VO}_{2}$, MR, RER, VE, HR, BLa) were significantly higher at a given RPE during UBP compared to ACE. Therefore, the greater physiological stress during UBP might be related to differences in local metabolic responses in the working upper-body muscles, such as a higher local oxygen desaturation and a lower local muscle blood flow (this is indicated by unpublished data from our research group), in response to the higher instantaneous power production during each stroke in the UBP compared to the ACE mode. However, further studies measuring local muscle blood flow and desaturation are needed to investigate this hypothesis.

\section{Differences between AB and PARA}

As expected, PARA displayed significantly lower $\mathrm{VO}_{2 \text { peak }}$ compared to $\mathrm{AB}$, which might partially be due to a more limited ability to recruit muscle mass during testing. Even though we tried to minimize differences in trunk and leg stabilization between PARA and AB, we still observed leg muscle contractions in $\mathrm{AB}$ especially towards the end of the incremental test. In addition, $\mathrm{VO}_{2 \text { peak }}$ might be lower in PARA due the inability to redistribute blood from the paralyzed trunk and lower limbs, which is related to a reduced stroke volume and, at maximal exercise intensities, to a reduced cardiac output (Hopman et al. 1992, 1993; Thijssen et al. 2009). In PARA with an injury level above Th6, $\mathrm{VO}_{2 \text { peak }}$ may be further restricted due to reduced blood redistribution from the splanchnic vascular bed (Thijssen et al. 2009). Furthermore, the lower $\mathrm{VO}_{2 \text { peak }}$ in PARA may be related to the fact that $\mathrm{AB}$ perform more overall training hours. Whereas the amount of upper-body training did not differ between PARA and AB and the two groups had a similar amount of muscle mass in the upper body, $A B$ had twice the amount of overall training hours due to additional exercise with lower-body- and whole-body exercise modes. Additionally, PARA consisted of a group of athletes from different sports, whereas $A B$ were all cross-country skiers. As such, PARA might be less specifically trained for the upper-body poling movement, and one might expect the difference in $\mathrm{VO}_{2 \text { peak }}$ to be bigger in UBP as compared to ACE. However, differences in $\mathrm{VO}_{\text {2peak }}$ were similar between PARA and AB both in UBP and ACE. This indicates that, when the 

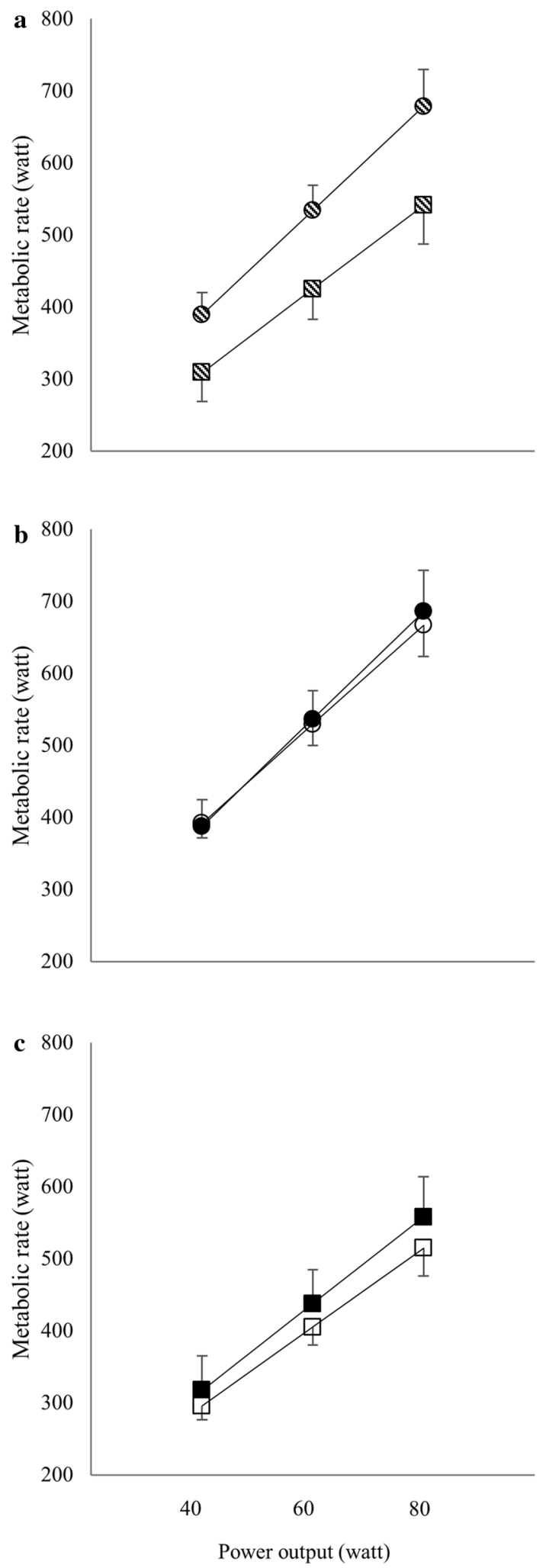

Fig. 3 Metabolic rate-work rate relationship in the comparisons of a upper-body poling (circles) and arm crank ergometry (squares) with paraplegic and able-bodied participants pooled, b paraplegic (open circles) and able-bodied participants (closed circles) in the upperbody poling mode, and $\mathbf{c}$ paraplegic (open squares) and able-bodied participants (closed squares) in the arm crank ergometry mode upper-body is restricted, sports-specificity does not seem to have a major effect on $\mathrm{VO}_{2 \text { peak }}$.

There was no difference in MR at a given PO between PARA and AB, indicating that PARA were equally efficient as $\mathrm{AB}$. In addition, $\mathrm{AB}$ had a higher $\mathrm{VO}_{2}$ but also a comparably higher absolute $\mathrm{PO}$ at all RPE-matched submaximal stages. Hence, as a $\%$ of $\mathrm{VO}_{2 \text { peak }}$ and of peak PO, participants exercised at the same relative intensity in both groups. Furthermore, none of the other physiological parameters significantly differed between PARA and AB when expressed as a percentage of peak values. Concluding from the above, differences in the submaximal responses between $\mathrm{AB}$ compared to PARA are due to AB working at higher $\mathrm{PO}$ and not due to differences in exercise efficiency.

\section{Methodological considerations}

While the fixed position of the upper body reduced potential differences in the use of the muscles of the trunk and pelvic region between UBP and ACE as well as AB and PARA, it likely influenced $\mathrm{VO}_{2 \text { peak }}$ and other related outcome parameters as well. Not restricting upper-body movement (as is more commonly seen when UBP is used during training and competition), would have led to a different use of the trunk in UBP compared to ACE, in particular in the comparison of PARA versus AB. In UBP, trunk movement can easily contribute to increased power production and thereby elevated MR (Hegge et al. 2015). In comparison, due to the asynchronous arm movements in ACE, there is a lower contribution of the trunk movement to power production. Further studies are needed to compare the effect of fixed trunk versus allowing the trunk to move freely on $\mathrm{VO}_{2 \text { peak }}$ during UBP incremental exercise to exhaustion.

\section{Conclusion}

In upper-body trained PARA and $\mathrm{AB}$ participants, $\mathrm{VO}_{2 \text { peak }}$ did not differ between UBP and ACE, indicating that the movement patterns of these two test modes tax the cardiovascular system to a similar extent when the trunk is fixed. The $19 \%$ lower peak PO in UBP compared to ACE may be explained by the coinciding lower efficiency in UBP. Furthermore, the lower $\mathrm{VO}_{2 \text { peak }}$ in PARA compared to $\mathrm{AB}$ is likely related to their disability, i.e. less active muscle mass during testing and a limited blood redistribution below the level of injury. However, there was no difference in exercise efficiency between PARA and AB in the two modes. Overall, the findings of this study provide a good starting point for understanding the differences in outcome parameters between two commonly used test modes and between PARA and $\mathrm{AB}$ athletes. However, to allow coaches and researchers to implement our findings into practice, future research 
should complement our results by investigating whether differences in trunk involvement between UBP and ACE lead to differences in $\mathrm{VO}_{2 \text { peak }}$ and efficiency.

Acknowledgements We appreciate the time and effort of the participants who took part in this study. Furthermore, we thank Katrin Daetwyler and Knut Skovereng for their assistance in the laboratory.

Author contributions JKB, LG, GE, ØS conceived and designed the research. LG and JKB conducted the experiment. JKB and LG analyzed the data and wrote the manuscript, with $\varnothing \mathrm{S}$ and GE revising the manuscript critically for important intellectual content. All authors read and approved the manuscript.

Funding This study was funded by the Centre for Elite Sports Research, Department of Neuromedicine and Movement Science, Norwegian University of Science and Technology. The laboratory facilities and equipment were provided by NeXt Move, Norwegian University of Science and Technology (NTNU). NeXt Move is funded by the Faculty of Medicine at NTNU and Central Norway Regional Health Authority. The funders had no role in study design, data collection and analysis, decision to publish, or preparation of the manuscript.

\section{Compliance with ethical standards}

Conflict of interest The authors declare no financial or non-financial conflicts of interest.

Open Access This article is distributed under the terms of the Creative Commons Attribution 4.0 International License (http://creativeco mmons.org/licenses/by/4.0/), which permits unrestricted use, distribution, and reproduction in any medium, provided you give appropriate credit to the original author(s) and the source, provide a link to the Creative Commons license, and indicate if changes were made.

\section{References}

Arabi H, Vandewalle H, Pitor P, de Lattre J, Monod H (1997) Relationship between maximal oxygen uptake on different ergometers, lean arm volume and strength in paraplegic subjects. Eur J Appl Physiol Occup Physiol 76(2):122-127. https://doi.org/10.1007/ s004210050223

Atkinson G, Reilly T (1996) Circadian variation in sports performance. Sports Med 21(4):292-312

Bloemen MA, de Groot JF, Backx FJ, Westerveld RA, Takken T (2015) Arm cranking versus wheelchair propulsion for testing aerobic fitness in children with spina bifida who are wheelchair dependent. J Rehabil Med 47(5):432-437. https://doi.org/10.2340/16501 977-1944

Borg GA (1982) Psychophysical bases of perceived exertion. Med Sci Sports Exerc 14(5):377-381

Drory Y, Ohry A, Brooks ME, Dolphin D, Kellermann JJ (1990) Arm crank ergometry in chronic spinal cord injured patients. Arch Phys Med Rehabil 71(6):389-392

Ettema G, Loras HW (2009) Efficiency in cycling: a review. Eur J Appl Physiol 106(1):1-14. https://doi.org/10.1007/s00421-009-1008-7

Gass GC, Camp EM (1984) The maximum physiological responses during incremental wheelchair and arm cranking exercise in male paraplegics. Med Sci Sports Exerc 16(4):355-359

Gass EM, Harvey LA, Gass GC (1995) Maximal physiological responses during arm cranking and treadmill wheelchair propulsion in T4-T6 paraplegic men. Paraplegia 33(5):267-270. https://doi.org/10.1038/sc.1995.60

Gayle GW, Pohlman RL, Glaser RM, Davis GM (1990) Cardiorespiratory and perceptual responses to arm crank and wheelchair exercise using various handrims in male paraplegics. Res Q Exerc Sport 61(3):224-232. https://doi.org/10.1080/02701 367.1990 .10608683

Glaser RM, Sawka MN, Brune MF, Wilde SW (1980) Physiological responses to maximal effort wheelchair and arm crank ergometry. J Appl Physiol Respir Environ Exerc Physiol 48(6):1060-1064

Hegge AM, Bucher E, Ettema G, Faude O, Holmberg HC, Sandbakk O (2015) Gender differences in power production, energetic capacity and efficiency of elite cross-country skiers during wholebody, upper-body, and arm poling. Eur J Appl Physiol. https://doi. org/10.1007/s00421-015-3281-y

Hintzy F, Tordi N, Perrey S (2002) Muscular efficiency during arm cranking and wheelchair exercise: a comparison. Int J Sports Med 23(6):408-414. https://doi.org/10.1055/s-2002-33734

Hopman MT, Oeseburg B, Binkhorst RA (1992) Cardiovascular responses in paraplegic subjects during arm exercise. Eur J Appl Physiol Occup Physiol 65(1):73-78

Hopman MT, Verheijen PH, Binkhorst RA (1993) Volume changes in the legs of paraplegic subjects during arm exercise. J Appl Physiol (1985) 75(5):2079-2083. https://doi.org/10.1152/jappl 1993.75.5.2079

Hopman MT, Houtman S, Groothuis JT, Folgering HT (2004) The effect of varied fractional inspired oxygen on arm exercise performance in spinal cord injury and able-bodied persons. Arch Phys Med Rehabil 85(2):319-323

Leicht C, Perret C (2008) Comparison of blood lactate elimination in individuals with paraplegia and able-bodied individuals during active recovery from exhaustive exercise. J Spinal Cord Med 31(1):60-64. https://doi.org/10.1080/10790268.2008.11753982

Leicht CA, Tolfrey K, Lenton JP, Bishop NC, Goosey-Tolfrey VL (2013) The verification phase and reliability of physiological parameters in peak testing of elite wheelchair athletes. Eur J Appl Physiol 113(2):337-345. https://doi.org/10.1007/s0042 1-012-2441-6

Martel G, Noreau L, Jobin J (1991) Physiological responses to maximal exercise on arm cranking and wheelchair ergometer with paraplegics. Spinal Cord 29(7):447-456

McCafferty WB, Horvath SM (1977) Specificity of exercise and specificity of training: a subcellular review. Res Q 48(2):358-371

Mossberg K, Willman C, Topor MA, Crook H, Patak S (1999) Comparison of asynchronous versus synchronous arm crank ergometry. Spinal Cord 37(8):569-574

Mukherjee G, Samanta A (2001) Physiological response to the ambulatory performance of hand-rim and arm-crank propulsion systems. J Rehabil Res Dev 38(4):391-399

Peronnet F, Massicotte D (1991) Table of nonprotein respiratory quotient: an update. Can J Sport Sci 16(1):23-29

Price M, Campbell I (1999a) Thermoregulatory responses of spinal cord injured and able-bodied athletes to prolonged upper body exercise and recovery. Spinal Cord 37(11):772-779

Price MJ, Campbell IG (1999b) Thermoregulatory and physiological responses of wheelchair athletes to prolonged arm crank and wheelchair exercise. Int J Sports Med 20(7):457-463. https://doi. org/10.1055/s-1999-8831

Price MJ, Bottoms L, Smith PM, Nicholettos A (2011) The effects of an increasing versus constant crank rate on peak physiological responses during incremental arm crank ergometry. J Sports Sci 29(3):263-269. https://doi.org/10.1080/02640414.2010.525520

Sawka MN (1986) Physiology of upper body exercise. Exerc Sport Sci Rev 14:175-211 
Sawka MN, Glaser RM, Wilde SW, von Luhrte TC (1980) Metabolic and circulatory responses to wheelchair and arm crank exercise. J Appl Physiol 49(5):784-788

Smith PM, Price MJ, Doherty M (2001) The influence of crank rate on peak oxygen consumption during arm crank ergometry. J Sports Sci 19(12):955-960. https://doi.org/10.1080/026404101317108 453

Smith PM, Doherty M, Drake D, Price MJ (2004) The influence of step and ramp type protocols on the attainment of peak physiological responses during arm crank ergometry. Int J Sports Med 25(8):616-621. https://doi.org/10.1055/s-2004-817880

Smith PM, Amaral I, Doherty M, Price MJ, Jones AM (2006) The influence of ramp rate on $\mathrm{VO}_{2}$ peak and "excess" $\mathrm{VO}_{2}$ during arm crank ergometry. Int J Sports Med 27(8):610-616. https://doi. org/10.1055/s-2005-865857
Smith PM, Doherty M, Price MJ (2007) The effect of crank rate strategy on peak aerobic power and peak physiological responses during arm crank ergometry. J Sports Sci 25(6):711-718. https://doi. org/10.1080/02640410600831955

Taylor HL, Buskirk E, Henschel A (1955) Maximal oxygen intake as an objective measure of cardio-respiratory performance. J Appl Physiol 8(1):73-80

Thijssen DH, Steendijk S, Hopman MT (2009) Blood redistribution during exercise in subjects with spinal cord injury and controls. Med Sci Sports Exerc 41(6):1249-1254. https://doi.org/10.1249/ MSS.0b013e318196c902

Tropp H, Samuelsson K, Jorfeldt L (1997) Power output for wheelchair driving on a treadmill compared with arm crank ergometry. Br J Sports Med 31(1):41-44 